\title{
Inhibition of PI-3-K and AKT Amplifies Kv1.3 Inhibitor-Induced Death of Human T Leukemia Cells
}

\author{
Tim Bergermann $^{\mathrm{a}} \quad$ Lukas Born $^{\mathrm{a}} \quad$ Fiona Ferguson $^{\mathrm{a}}$ Paula Latkovic ${ }^{\mathrm{a}}$ \\ Alexandra Scheul ${ }^{a} \quad$ Nina Sonnenschein ${ }^{a}$ Luigi Leanza $^{b}$ Simone Keitsch ${ }^{c}$ \\ Carolin Sehl $^{c}$ Barbara Wilker ${ }^{c}$ Michael J. Edwards ${ }^{d}$ Mario Zoratti ${ }^{, f}$ \\ Cristina Paradisig Markus Kohnen ${ }^{a} \quad$ Ildiko Szabo ${ }^{b, f} \quad$ Katrin Anne Becker ${ }^{c}$ \\ Alexander Carpinteiroch
}

\begin{abstract}
a'Gymnasium Essen-Werden, Essen-Werden, Germany, bDepartment of Biology, University of Padova, Padova, Italy, 'Department of Molecular Biology, University Hospital, Medical School, University of Duisburg-Essen, Essen, Germany, dDepartment of Surgery, University of Cincinnati, Cincinnati, $\mathrm{OH}$, USA, e Department of Biomedical Sciences, University of Padova, Padova, Italy, ${ }^{\mathrm{f} C N R}$ Institute of Neuroscience, Padova, Italy, 9Department of Chemical Sciences, University of Padova, Padova, Italy, hDepartment of Hematology, University Hospital Essen, Essen, Germany
\end{abstract}

\section{Key Words}

Kv1.3 • Mitochondria $\cdot$ Lymphoma $•$ Signaling $\cdot$ Cell death

\begin{abstract}
Background/Aims: We have previously shown that inhibition of the mitochondrial Kv1.3 channel results in an initial mitochondrial hyperpolarization and a release of oxygen radicals that mediate mitochondrial depolarization, cytochrome $c$ release and death. Here, we investigated whether inhibition of Kv1.3 channels can also induce cellular resistance mechanisms that counteract the induction of cell death under certain conditions. Methods: We treated leukemic T cells with the mitochondria-targeted Kv1.3 inhibitor PCARBTP and determined the activity of different kinases associated with cell survival including ZAP70, PI-3-K, AKT, JNK and ERK by measuring the activation-associated phosphorylation of these proteins. Furthermore, we inhibited AKT and JNK and determined the effect of PCARBTP-induced tumor cell death. Results: We demonstrate that treatment of Jurkat $T$ leukemia cells with low doses of the mitochondria-targeted inhibitor of Kv1.3 PCARBTP $(0.25 \mu \mathrm{M}$ or $1 \mu \mathrm{M})$ for 10 minutes induced a constitutive phosphorylation/activation of the pro-survival signaling molecules ZAP70, PI$3-K$, AKT and JNK, while the phosphorylation/activation of ERK was not affected. Stimulation of Jurkat cells via the TCR/CD3 complex induced an additional activation of a similar pattern
\end{abstract}

T. Bergermann, L. Born, F. Ferguson, P. Latkovic, A. Scheul and N. Sonnenschein contributed equally to this article. 
of signaling events. Higher doses of the Kv1.3 inhibitor, i.e. $10 \mu \mathrm{M}$ PCARBTP, reduced the basal phosphorylation/activation of these signaling molecules and also impaired their activation upon stimulation via the TCR/CD3 complex. A low dose of PCARBTP, i.e. $0.25 \mu \mathrm{M}$ PCARBTP, was almost without any effect on cell death. In contrast, concomitant inhibition of PI-3-K or AKT greatly sensitized Jurkat leukemia cells to the Kv1.3 inhibitor PCARBTP and allowed induction of cell death already at $0.25 \mu \mathrm{M}$ PCARBTP. Conclusion: These studies indicate that Jurkat leukemia cells respond to low doses of the mitochondria-targeted Kv1.3 inhibitor PCARBTP with an activation of survival signals counteracting cell death. Inhibition of these T cell survival signals sensitizes leukemia cells to death induced by mitochondria-targeted Kv1.3 inhibitors. High doses of the Kv1.3 inhibitor inactivate these signals directly permitting death.

(C) 2019 The Author(s). Published by Cell Physiol Biochem Press GmbH\&Co. KG

\section{Introduction}

Mitochondria are key organelles in the regulation of cell death induced by many stress stimuli and endogenous apoptosis pathways [1]. Apoptotic cell death is often initiated by translocation of Bax to mitochondria, where the protein is integrated into the outer mitochondrial membrane [2, 3]. Likewise Bak, a homologue of Bax, which is usually loosely associated with the outer mitochondrial membrane, integrates into the membrane upon induction of apoptosis [3].

We have previously shown that the potassium channel Kv1.3 is expressed in mitochondria and serves as target for Bax and Bak proteins to mediate apoptosis [4-10]. Expression of Kv1.3 in the inner mitochondrial membrane was shown by us and others in a variety of cells including lymphocytes, hippocampal neurons, macrophages, leukemia cells, melanoma and pancreas cells $[6,8,11-13]$.

A structural model of the membrane-integrated Bax described that the amino acids 127 and 128 of Bax protrude from the outer mitochondrial membrane into the intermembrane space [2]. We have demonstrated that the amino acid 128 in Bax, a lysine residue, folds into the pore of the mitochondrial Kv1.3 channel, inhibits the channel and thereby induces a hyperpolarization of the inner mitochondrial membrane $[4,5,9,10]$. The hyperpolarization of the inner mitochondrial membrane results in a release of reactive oxygen species in mitochondria, which mediate an opening of the permeability transition pore and a subsequent depolarization of mitochondria [4-6, 9, 10]. In addition, inhibition of Kv1.3 mediates a release of cytochrome $c$ with participation of the permeability transition pore [9].

Membrane-permeable inhibitors of Kv1.3, for instance PAP-1, Psora-4 and clofazimine mimic the effects of Bax and Bak on mitochondrial Kv1.3 [4, 5, 9, 10]. These Kv1.3 inhibitors induce cell death, in particular in tumor cells, although they are not specifically targeting the mitochondria-located Kv1.3 channels. To improve specificity, we have recently synthesized several novel inhibitors of Kv1.3 that are specifically targeting mitochondria due to their positive charge [6]. These compounds are PAP1-derivatives containing a lipophilic, positively charged triphenylphosphonium group $\left(\mathrm{TPP}^{+}\right)$resulting in their accumulation in mitochondria. These compounds specifically killed primary chronic B-lymphocytic leukemia tumor cells, while survival of healthy B cells was not compromised [6]. Moreover, in vivo in melanoma and pancreatic ductal adenocarcinoma models these Kv1.3 inhibitors reduced the tumor size by more than $90 \%$ and $60 \%$, respectively, without a significant effect on normal cells $[4,6]$. This was attributed to a hyperpolarized mitochondrial membrane potential in tumor cells resulting in a higher sensitivity to a further hyperpolarization upon Kv1.3 inhibition and to a higher basal reactive oxygen species (ROS) level in cancer cells with respect to healthy cells. Therefore, in cancer cells expressing higher levels of Kv1.3, channelinhibition induced ROS production was sufficiently high to drive the cells to death $[5,6]$.

We have recently shown that sub-lethal concentration of PAPTP decreases Wnt signaling [7], possibly contributing to the accentuated anti-tumor effect of this drug. However, at present it is unknown whether these drugs used at very low concentrations impact on other signaling pathways that might counteract cell death induced by mitochondria-targeted 


\section{Cellular Physiology Cell Physiol Biochem 2019;53(S1):1-10

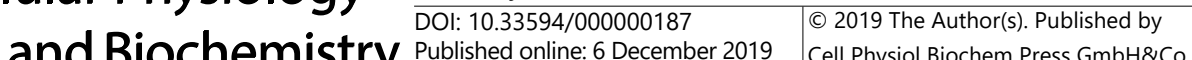 \\ \begin{tabular}{l|l} 
Published online: 6 December 2019 & Cell Physiol Biochem Press GmbH\&Co. KG \\
\hline
\end{tabular} \\ Bergermann et al.: Kv1.3-Induced Death of Lymphoma Cells}

Kv1.3 inhibitors. The identification of such pathways may allow the use of lower doses of Kv1.3 inhibitors by sensitizing tumor cells to cell death induced by Kv1.3 inhibition, without increasing side effects. This is very important, since Kv1.3 blockers may have cardiac effects, which may limit dose escalation.

Here, we demonstrate that the mitochondria-targeted Kv1.3 inhibitor PCARBTP regulates several survival signaling pathways in Jurkat leukemia cells prior and after stimulation of the TCR/CD3 complex. The inhibition of these pathways sensitizes the leukemia cells to death induced by inhibition of mitochondrial Kv1.3 by PCARBTP.

\section{Materials and Methods}

\section{Cell culture}

Jurkat cells were grown in RPMI-1640 supplemented with $10 \%$ fetal calf serum, $10 \mathrm{mM}$ HEPES (pH 7.4), $2 \mathrm{mM}$ L-glutamine, $1 \mathrm{mM}$ sodium pyruvate, $100 \mu \mathrm{M}$ non-essential amino acids, 100 units/ml penicillin, $100 \mu \mathrm{g} / \mathrm{ml}$ streptomycin (all Life Technologies) and $50 \mu \mathrm{M} \beta$-mercaptoethanol. Cells were grown to a density of approximately 500, 000 cells $/ \mathrm{ml}$ and then split. All cultures were re-established from frozen stocks after 4 weeks of growth to prevent selection of clones.

\section{Cell death assays}

Cell death was determined by FITC-Annexin V (Roche) staining. Cells were incubated for 24, 48, 72 or $96 \mathrm{hrs}$ with $0.25 \mu \mathrm{M}, 1 \mu \mathrm{M}$ or $10 \mu \mathrm{M}$ PCARBTP in RPMI-1640 supplemented as above. Cells were then washed twice in a buffer consisting of $10 \mathrm{mM}$ HEPES (pH 7.3), $140 \mathrm{mM} \mathrm{NaCl}$ and $5 \mathrm{mM} \mathrm{CaCl}_{2}(\mathrm{H} / \mathrm{S}$ ). The cells were resuspended in $100 \mu \mathrm{L}$ washing buffer containing FITC-Annexin $V$ at a dilution of 1:100. Cells were incubated for $15 \mathrm{~min}$ at room temperature, $100 \mu \mathrm{L}$ of washing buffer was added and the cells were analyzed for binding of FITC-Annexin $V$ by flow cytometry using a FACS-Calibur (BD).

In addition, morphological signs of apoptosis, i.e. DNA condensation, nuclear fragmentation and blebbing, were determined by Trypan blue. At least 200 cells were counted and the percentage of dead cells was calculated.

\section{Cell stimulations}

Jurkat cells were washed twice in H/S consisting of $132 \mathrm{mM} \mathrm{NaCl}, 20 \mathrm{mM}$ HEPES [pH 7.4], $5 \mathrm{mM} \mathrm{KCl}$, $1 \mathrm{mM} \mathrm{CaCl}{ }_{2}, 0.7 \mathrm{mM} \mathrm{MgCl}, 0.8 \mathrm{mM} \mathrm{MgSO}_{4}$ and resuspended in $\mathrm{H} / \mathrm{S}$. Cells were then aliquoted with $1.5 \times 10^{5}$ cells per $100 \mu \mathrm{l} / \mathrm{S}$, and $0.25 \mu \mathrm{M}, 1 \mu \mathrm{M}$ or $10 \mu \mathrm{M}$ PCARBTP or DMSO, i.e. the solvent, were added. The samples were incubated for $10 \mathrm{~min}$ at $37^{\circ} \mathrm{C}$. The samples were then stimulated with $1 \mu \mathrm{g} / \mathrm{mL}$ OKT3 antiCD3 antibodies as indicated. The samples were finally lysed in $25 \mathrm{mM}$ Tris- $\mathrm{HCl}$ (pH 7.4), $125 \mathrm{mM} \mathrm{NaCl}, 10$ mM EDTA, $10 \mathrm{mM}$ sodiumpyrophosphate, 3\% IGEPAL, $10 \mu \mathrm{g} / \mathrm{mL}$ each of aprotinin and leupeptin and 10 $\mathrm{mM} \mathrm{Na}_{3} \mathrm{VO}_{4}$ (abbreviated TN3) for $5 \mathrm{~min}$ at $4^{\circ} \mathrm{C}$ and centrifuged at $14,000 \mathrm{rpm}$ for $5 \mathrm{~min}$ at $4^{\circ} \mathrm{C}$, after which $5 \mu \mathrm{L} 5 \mathrm{x}$ SDS-Laemmli buffer was added. Cell lysates were boiled and analyzed by sodium dodecyl sulfate polyacrylamide gel electrophoresis (SDS-PAGE).

\section{Western blots}

Cell lysates were thawed and proteins were separated by 7.5\% -10\% SDS-PAGE. Proteins were transferred onto nitrocellulose overnight. The blots were then blocked in Starting Block Solution (Pierce) for $45 \mathrm{~min}$ at room temperature, washed twice $10 \mathrm{~min}$ each in Tris-buffered saline supplemented with 0.05\% Tween 20 (TBS-Tween) and incubated for $45 \mathrm{~min}$ at room temperature with anti-phosphotyrosine antibodies, clone 4G10 (1:1000 dilution, Millipore), anti-phospho-ZAP70 (1:1000 dilution, Cell Signaling), anti-phospho-PI-3-K (1:1000 dilution, Cell Signaling), anti-phospho-AKT (1:1000 dilution, Cell Signaling), anti-phospho-PLC $\gamma$ (1:1000 dilution, Cell Signaling), anti-phospho-p38K (1:1000 dilution, Cell Signaling) or anti-phospho-JNK (Thr183/Tyr185) (1:1000 dilution, Cell Signaling). Antibodies were diluted in H/S supplemented with $1 \%$ Starting Block Solution. The blots were then washed 5-times for 10 min each in TBS-Tween and incubated for 45 min with horse-radish peroxidase (HRP)-coupled secondary antibodies (Santa Cruz Inc). The blots were washed again $5 \mathrm{x}$ for $10 \mathrm{~min}$ each in TBS-Tween and developed employing a chemoluminescence system. Western blots were quantified using Image J. 


\section{PI-3-K and AKT inhibition}

To inhibit PI-3-K, we used the inhibitor LY 294002 (Sigma) and to inhibit AKT we employed the AKT1/2 inhibitor 1, 3-Dihydro1-(1((4-(6-phenyl-1H-imidazo [4, 5-g] quinoxalin-7-yl) phenyl) methyl) -4-piperidinyl) -2H-benzimidazol-2-one trifluoro-acetate salt hydrate (Sigma). The inhibitors were added to Jurkat cells $15 \mathrm{~min}$ prior to addition of $0.25 \mu \mathrm{M}$ PCARBTP. Cells were incubated for $24 \mathrm{hrs}$ and cell death was determined by FITC-Annexin V staining and flow cytometry as above.

\section{Statistics}

All data are expressed as arithmetic mean \pm SD of 4 independent studies or are representative of at least 4 similar studies. For multiple comparisons, we used one-way ANOVA followed by post-hoc Student's t-tests for all pairwise comparisons applying Bonferroni correction for multiple testing. All values were normally distributed. The statistical details (n-numbers, mean \pm SD and tests) are given in the figure legends.

\section{Results}

We have previously shown that inhibition of mitochondrial Kv1.3 channels induces an initial hyperpolarization of mitochondria, followed by a release of reactive oxygen species, a mitochondrial depolarization and a release of cytochrome c [4-10]. Here we tested whether inhibition of mitochondrial Kv1.3 also impacts the activity of survival and stress signaling pathways in human $\mathrm{T}$ leukemia cells under resting conditions and after stimulation of the cells via the TCR/CD3 complex, a prototypic growth factor receptor. Important prosurvival signaling pathways in T cells are the activation of Src-like tyrosine kinase with the subsequent tyrosine phosphorylation of multiple intracellular proteins, activation of ZAP70 and PLC $\gamma$ (leading to diacylglyerol formation), ERK, PI-3-K and AKT kinases as well as the stress response kinase JNK [7]. These pathways were therefore tested in the present study to test the hypothesis that Jurkat cells respond with activation of these pro-survival pathways to counteract the death-inducing effects of mitochondrial Kv1.3 inhibition.

Treatment with sub-lethal, lower concentrations of the Kv1.3 inhibitor PCARBTP induced a dose dependent increase of the tyrosine phosphorylation of cellular proteins as determined by western blotting of total cell lysates (Fig. 1a). Higher concentrations of the Kv1.3 inhibitor PCARBTP induced a decrease of basal cellular tyrosine phosphorylation (Fig. 1a). Stimulation of Jurkat T leukemia cells with OKT-3 anti-CD3 antibodies resulted in tyrosine phosphorylation of several cellular proteins, which was only slightly affected by a 10 minute pre-incubation with low concentrations of PCARBTP, while higher concentrations of the inhibitor greatly reduced cellular tyrosine phosphorylation induced by CD3 stimulation (Fig. 1a). Blotting of an aliquot of the cell lysates with anti-actin antibody confirmed that similar amounts of protein were loaded (Fig. 1a).

ZAP70 is one of the earliest signaling molecules activated upon TCR/CD3 stimulation [14]. ZAP70 regulates multiple pathways and functions as a key signaling molecule of the TCR/CD3 receptor [14]. We therefore tested whether phosphorylation of ZAP70, which reflects its activity, is altered by PCARBTP. Interestingly, lower doses of PCARBTP induced a constitutive phosphorylation/activation of ZAP70, which was further increased by TCR/CD3 ligation (Fig. 1b). In contrast, higher doses of PCARBTP reduced TCR/CD3-ligation induced phosphorylation/activation of ZAP70 (Fig. 1b). Untreated cells responded with a marked phosphorylation/activation of ZAP70 upon TCR/CD3-stimulation (Fig. 1b). Here and in the following experiments, we show aliquots of the same samples shown in Fig. 1a. Thus, the normalization to actin is shown in Fig. 1 a.

A similar constitutive phosphorylation/activation induced by low concentrations of PCARBTP was also observed for PLC $\gamma$ (Fig. 1c). Stimulation via the TCR/CD3 complex further enhanced the phosphorylation/activation of PLC $\gamma$ (Fig. 1c).

The activation of ERK links the TCR/CD3 complex with activation of $N F \kappa B$, at least in $\mathrm{T}$ cells, and thereby to gene transcription and proliferation. TCR/CD3-ligation induced a marked phosphorylation/activation of this kinase (Fig. 1d). Lower doses of the mitochondrial 


\section{Cellular Physiology Cell Physiol Biochem 2019;53(S1):1-10 \begin{tabular}{ll|l|l|l|l} 
DOI: 10.33594/000000187 & ( 2019 The Author(s). Published by
\end{tabular}

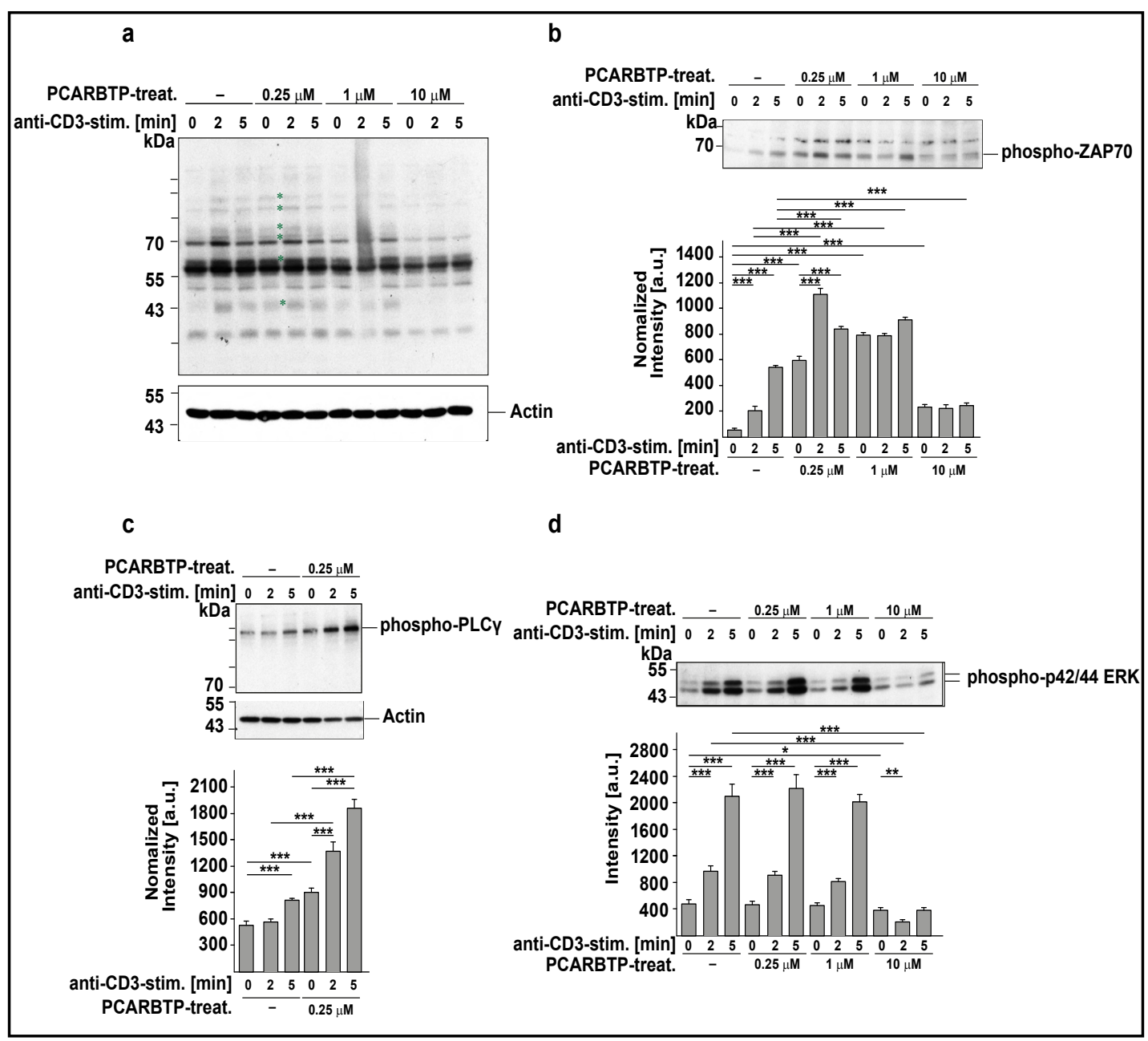

Fig. 1. Mitochondria-targeted Kv1.3 inhibitors induce basal tyrosine phosphorylation of several cellular proteins including ZAP70 and PLC $\gamma$. Jurkat cells were left untreated or treated with $0.25 \mu \mathrm{M}, 1 \mu \mathrm{M}$ or 10 $\mu \mathrm{M}$ PCARBTP in the presence or absence of the anti-CD3 antibody OKT-3 $(1 \mu \mathrm{g} / \mathrm{mL})$ for the indicated times. Cells were lysed, insoluble material was removed, the samples were separated on 7.5 - 10\% SDS-PAGE and blotted for cellular tyrosine phosphorylation (a), phospho-ZAP70 (b), phospho-PLC $\gamma$ (c) or phospho-ERK (d). Asterisks in panel a indicate proteins that show an increased tyrosine phosphorylation after treatment with low doses of PCARBTP. Blots determining phospho-ZAP70, phospho-PLC $\gamma$ or phospho-ERK were quantified using Image J. The quantification is shown in the bar graphs in each Fig.. Panel d shows the quantification of $\mathrm{p} 42$, the results for $\mathrm{p} 44$ are very similar (not shown). The results show a constitutive phosphorylation/ activation of several cellular proteins including ZAP70 and PLC $\gamma$ after treatment with low doses of PCARBTP. (c) Neither basal nor OKT-3-induced phosphorylation of ERK is altered by treatment with low doses of PCARBTP. High concentrations $(10 \mu \mathrm{M})$ of PCARBTP reduce basal and OKT-3 induced cellular tyrosine phosphorylation. Aliquots of the samples were blotted for actin to show that similar amounts of proteins were loaded in all gels. Panel a, c, and d were performed from the same aliquots and the corresponding actin blot is displayed in panel a. Shown are representative blots from 4 independent studies or the mean \pm SD, $\mathrm{n}=4,{ }^{*} \mathrm{p}<0.05,{ }^{* *} \mathrm{p}<0.01,{ }^{* * *} \mathrm{p}<0.001$, ANOVA.

Kv1.3 inhibitor did not alter phosphorylation of ERK prior or after stimulation via CD3 (Fig. 1d). Higher doses of PCARBTP abrogated the stimulatory effect of CD3-stimulation on ERK phosphorylation/activity.

The PI-3-K/AKT pathway is a signaling pathway in T lymphocytes that is tightly linked to survival and proliferation $[8,14]$. Analysis of the effects of PCARBTP on this pathway revealed that the Kv1.3 inhibitor PCARBTP induced a constitutive activation of PI-3-K and 
AKT at all doses (Fig. 2a and b). This constitutive phosphorylation of PI-3-K did not further increase after TCR/CD3 ligation in the presence of PCARBTP suggesting that the maximal phosphorylation was reached. In contrast, the PCARBTP-increased basal phosphorylation/ activation of AKT further increased after TCR/CD3 mediated cell activation (Fig. 2a and b).

Jun N-terminal kinases (JNK) function as signaling molecules that integrate many stress signals, but also serve to mediate activation of the transcription factors c-Jun and AP-1 [15, 16 , 17]. Jurkat leukemia cells exhibited a constitutive phosphorylation of JNK, which was again used as readout for the activity of the kinase. Ligation of the TCR/CD3 complex by OKT3 antibodies resulted in a further increase of JNK phosphorylation reflecting its activation (Fig. 2c). Treatment with lower doses of PCARBTP, i.e. $0.25 \mu \mathrm{M}$ and $1 \mu \mathrm{M}$ PCARBTP, induced a constitutive phosphorylation of JNK even in cells not stimulated via CD3 (Fig. 2c). This phosphorylation was not further increased by OKT-3 stimulation (Fig. 2c). In contrast, $10 \mu \mathrm{M}$ PCARBTP did not change the basal phosphorylation of JNK, but completely abrogated TCR/ CD3-mediated activation of the kinase (Fig. 2c).

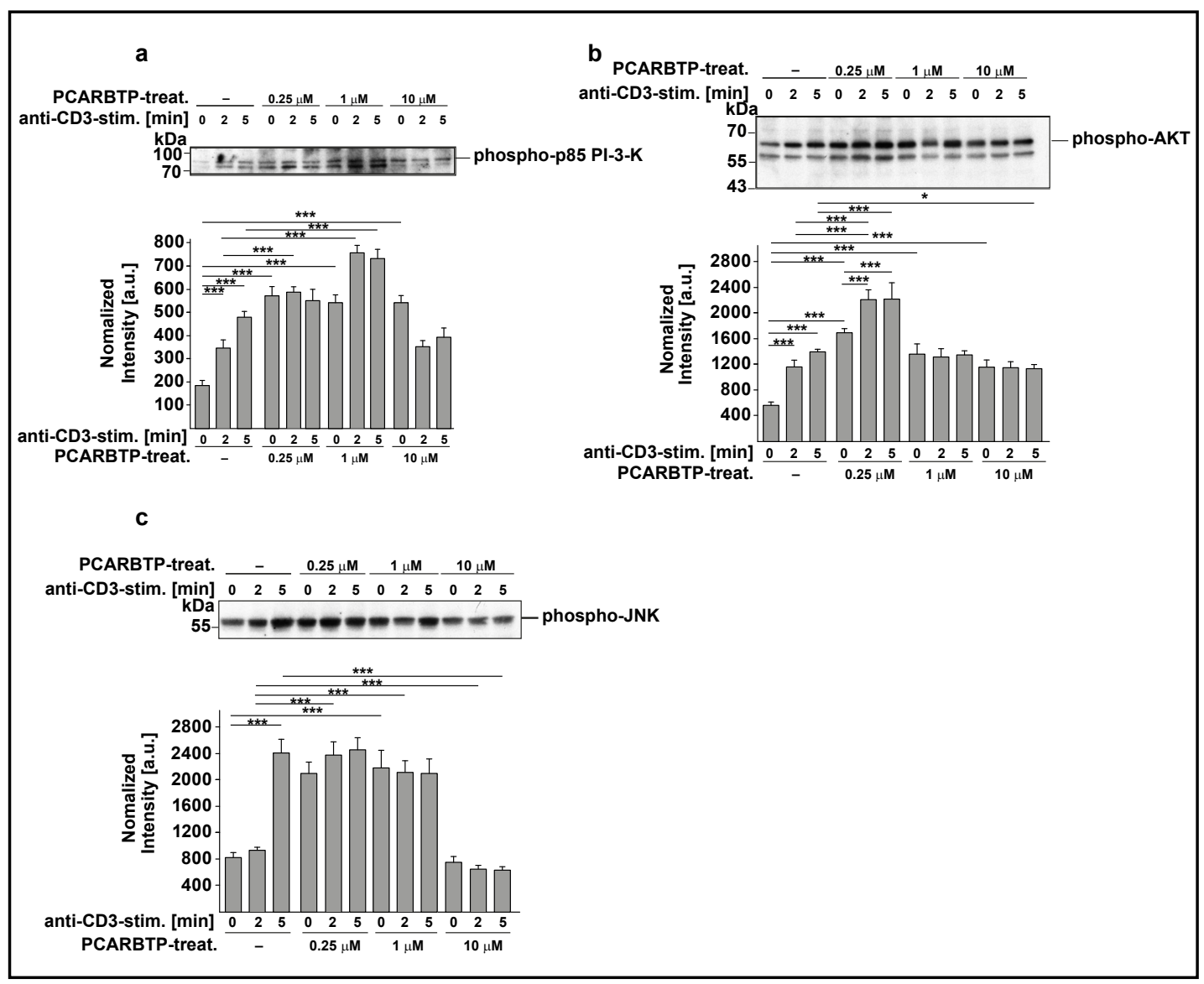

Fig. 2. Mitochondria-targeted Kv1.3 inhibitors induce tyrosine phosphorylation of PI-3-K, AKT and JNK. Jurkat cells were left untreated or treated with $0.25 \mu \mathrm{M}, 1 \mu \mathrm{M}$ or $10 \mathrm{M}$ PCARBTP in the presence or absence of the anti-CD3 antibody OKT-3 $(1 \mu \mathrm{g} / \mathrm{mL})$ for the indicated times. Cells were lysed and proteins were separated by SDS-PAGE as above. Blots were developed for phospho-PI-3-K (p85) (a), phospho-AKT (b) or phospho-JNK (c). The results show a strong constitutive phosphorylation/activation of PI-3-K, AKT and JNK upon treatment with low doses of PCARBTP, which is only slightly further increased by OKT-3 stimulation.. Panels in Fig. 2. were performed from the same aliquots as in Fig. 1a and the corresponding actin blot is displayed in Fig. 1a. Blots were again quantified using Image J, which is displayed in the bar graphs in each Fig... Displayed are representative blots from 4 independent studies or the mean $\pm S D, n=4,{ }^{*} p<0.05$, ${ }^{* *} \mathrm{p}<0.01,{ }^{* * *} \mathrm{p}<0.001$, ANOVA. 
These results indicate that treatment with very low doses of PCARBTP induces phosphorylation of several survival and stress signaling kinases, in particular of the PI-3-K/ Akt and the JNK pathway.

The data presented so far are short-term effects (up to 5 minutes following addition) of PCARBTP. To test for long-term effects of PCARBTP in Jurkat T leukemia cells, we investigated whether PCARBTP-treatment induces a dose-dependent cell death in Jurkat cells following at least $24 \mathrm{~h}$ incubation. While $0.25 \mu \mathrm{M}$ PCARBTP had no significant or only a slight effect on Jurkat cell death, $1 \mu \mathrm{M}$ and $10 \mu \mathrm{M}$ PCARBTP showed substantial toxicity and killed nearly $100 \%$ of Jurkat cells (Fig. 3a-c), in accordance with our previous data [6].

It has previously been shown that inhibition of PI-3-K and AKT senstizes cells to apotosis $[18,19,20,21]$. Therefore, we tested whether inhibition of the stress PI-3-K by the inhibitor LY 294002 sensitizes Jurkat cells to the effects of Kv1.3 inhibition. These cell death studies indicate that in the presence of the PI-3-K inhibitor LY 294002 already $0.25 \mu \mathrm{M}$ PCARBTP induced more than $75 \%$ cell death, while PCARBTP alone at this concentration was without significant impact on cell survival (Fig. 4).

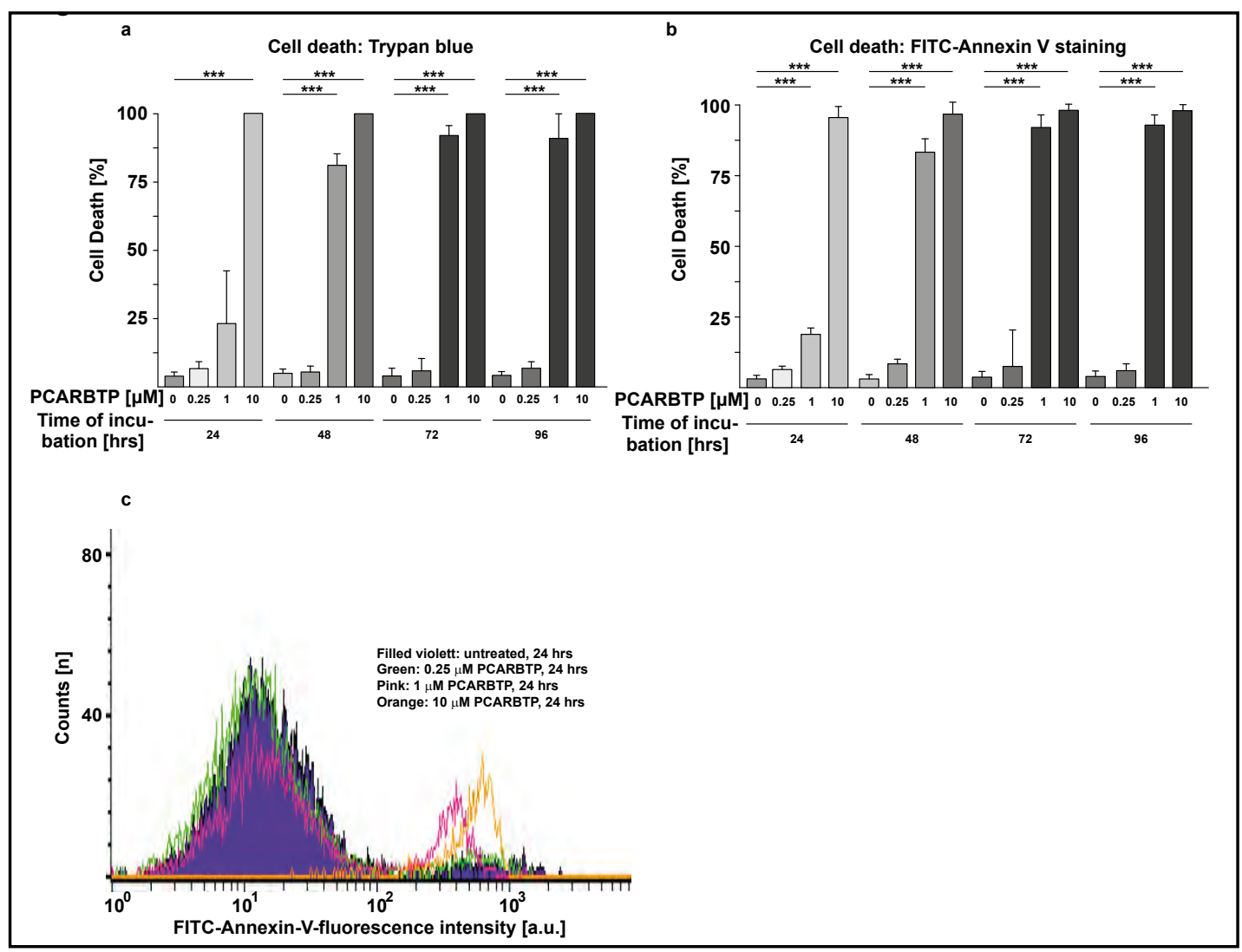

Fig. 3. Mitochondria-targeted Kv1.3 inhibitors induce a dose- and time-dependent cell death of Jurkat leukemia cells. Jurkat cells were left untreated or treated with $0.25 \mu \mathrm{M}, 1 \mu \mathrm{M}$ or $10 \mu \mathrm{M}$ PCARBTP for 24, 48, 72 or 96 hrs. Cell death was determined by Trypan Blue staining (a) or FITC-Annexin V staining and flow cytometry analysis (b). Panel c shows an example of the flow cytometry analysis. The fluorescence intensity is given in arbitrary units (a.u.). Given are the mean \pm SD of cell death in percent from total cells per sample; $\mathrm{n}=4,{ }^{*} \mathrm{p}<0.05,{ }^{* *} \mathrm{p}<0.01,{ }^{* * *} \mathrm{p}<0.001$, ANOVA. 


\begin{abstract}
Finally, we tested whether also the constitutive activation of AKT by low doses of PCARBTP contributes to prevention of cell death. To this end, we treated Jurkat cells with an AKT inhibitor and tested the induction of cell death by $0.25 \mu \mathrm{M}$ PCARBTP. The results indicated that AKT inhibition sensitized Jurkat cells to PCARBTP-induced cell death, even $0.25 \mu \mathrm{M}$ PCARBTP induced death to a significant extent in the presence of the AKT inhibitor (Fig. 4).
\end{abstract}

\section{Discussion}

The present data indicate a marked effect of the mitochondrial Kv1.3 inhibitor PCARBTP on the activity of important stress and survival pathways in Jurkat T leukemia cells prior or after TCR/CD3induced activation: Lower doses, i.e. $0.25 \mu \mathrm{M}$ or $1 \mu \mathrm{M}$, of the mitochondrial Kv1.3 inhibitor PCARBTP rapidly, i.e. within minutes, induced a constitutive activation of several signaling events in leukemia T cells, in particular AKT, PI-3-K and JNK. This activation was either additive to the stimulation triggered by TCR/CD3 ligation or already reached the maximal level with no further increase by OKT3-treatment. In contrast a high concentration of the drug reduced basal and TCR/CD3-induced stimulation of most cellular signaling molecules. Cell death, i.e. a long-term effect of PCARBTP treatment, was induced at higher concentration of PCARBTP that killed all cells within $24 \mathrm{hrs}$ at $10 \mu \mathrm{M}$ PCARBTP.

These data indicate a specific activation of the PI-3-K/AKT and JNK pathways by lower doses of the mitochondrial Kv1.3 inhibitor PCARBTP. Activation by lower doses of PCARBTP seems to counteract cell death, since inhibition of either PI3-3-K or AKT, respectively, greatly sensitized Jurkat cells to PCARBTP-induced death and even doses of $0.25 \mu \mathrm{M}$ PCARBTP induced up to $90 \%$ cell death, while this concentration was without significant effect if applied alone. Thus, we suggest that the activation of PI-3-K and AKT detected at lower concentrations of PCARBTP is part of the cellular response to Kv1.3 inhibition and serves to counteract cell death signals, although the mechanism how low dose of PCARBTP could exert an activatory effect on different kinases is not clear. In any case, inhibition of these signaling events facilitates activation of the death machinery induced by mitochondrial Kv1.3 inhibitors and, therefore, concomitant inactivation of these signaling pathways allows a much more efficient induction of cell death by Kv1.3 inhibitors.

The inhibition of ERK and JNK activation by high doses of PCARBTP does not seem to be mediated by induction of cell death, since we observe this inhibition already after 2 min, which is too early to be caused by apoptotic events.

At present it is unknown how an inhibition of PI-3-K and AKT contributes to the induction of cell death induced by inhibition of mitochondrial Kv1.3 and mitochondrial ROS. It is possible that inhibition of these pathways down-regulates survival pathways such as $\mathrm{NF \kappa B}$ or AP-1 [14]. However, it is also possible that the inactivation of these two kinases 
regulates the function of Bcl-2 like proteins $[8,9]$. Thus, in particular an inactivation of PI3-K/AKT may allow mitochondrial translocation and activation of Bax promoting apoptosis and/or an inactivation of anti-apoptotic Bcl-2 like proteins. Another possibility is that AKT indirectly modulates mitochondrial permeability transition pore opening via GSK-3 [22, 23]. It is also possible that AKT is recruited directly to the mitochondria where it could lead to a suppression of cytochrome c release, which would otherwise lead to apoptosis [24].

\section{Conclusion}

In summary, we demonstrate that treatment of Jurkat leukemia cells with low doses of the mitochondria-targeting Kv1.3 inhibitor PCARBTP results up-regulation of survival signals in T leukemia cells. Inhibition of these survival pathways sensitizes the leukemia cells to induction of cell death. High doses of PCARBTP inactivate these survival signals prior or after TCR/CD3-mediated cell activation, a process which seems to contribute to the induction of cell death by PCARBTP. It is to note that we have previously shown that PCARBTP rapidly induce changes in mitochondrial parameters, suggesting that the drug prevalently acts on the mitochondrial counterpart of the channel. Whether PCARBTP has these effects by acting on the plasma membrane Kv1.3 channels as well, or a mitochondria-dependent "retrograde" signaling leads to changes of PI-3-K, PLC $\gamma$, AKT and JNK activity, remains to be determined.

\section{Acknowledgements}

The study was supported by the GRK 2098 to KAB and EG and an AIRC20286 grant to IS.

\section{Author Contributions}

LL, MJE, MZ, CP, MK, IS, KAB and AC planned the studies and wrote the manuscript. TB, LB, FF, PL, AS, NS, SK, CS, BW, KAB and AC performed the experiments. All authors read the manuscript and commented on it.

\section{Disclosure Statement}

The authors declare to have no conflict of interest.

\section{References}

1 Szabo I, Zoratti M: Mitochondrial channels: ion fluxes and more. Physiol Rev 2014;94:519-608.

2 Annis MG, Soucie EL, Dlugosz PJ, Cruz-Aguado JA, Penn LZ, Leber B, Andrews DW: Bax forms multispanning monomers that oligomerize to permeabilize membranes during apoptosis. EMBO J 2005;24:2096-2103.

3 Antignani A, Youle RJ.: How do Bax and Bak lead to permeabilization of the outer mitochondrial membrane? Curr Opin Cell Biol 2006;18:685-689.

4 Leanza L, Henry B, Sassi N, Zoratti M, Chandy KG, Gulbins E, Szabo I: Inhibitors of mitochondrial Kv1.3 channels induce Bax/Bak-independent death of cancer cells. EMBO Mol Med 2012;4:577-593.

5 Leanza L, Trentin L, Becker KA, Frezzato F, Zoratti M, Semenzato G, Gulbins E, Szabo I: Clofazimine, Psora-4 and PAP-1, inhibitors of the potassium channel Kv1.3, as a new and selective therapeutic strategy in chronic lymphocytic leukemia. Leukemia 2013;27:1782-1785.

6 Leanza L, Romio M, Becker KA, Azzolini M, Trentin L, Managò A, Venturini E, Zaccagnino A, Mattarei A, Carraretto L, Urbani A, Kadow S, Biasutto L, Martini V, Severin F, Perutto R, Trimarco V, Egberts JH, Hauser C, Visentin A, et al.: Direct pharmacological targeting of a mitochondrial ion channel selectively kills tumor cells in vivo. Cancer Cell 2017;31:516-531. 


\section{Cellular Physiology Cell Physiol Biochem 2019;53(S1):1-10 \begin{tabular}{ll|l|l|l}
\hline DOI: 10.33594/000000187 & (O) 2019 The Author(s). Published by \\
\hline
\end{tabular} and Biochemistry Published online: 6 December 2019 Cell Physiol Biochem Press GmbH\&Co. KG \\ Bergermann et al.: Kv1.3-Induced Death of Lymphoma Cells}

7 Costa R, Peruzzo R, Bachmann M, Montà GD, Vicario M, Santinon G, Mattarei A, Moro E, Quintana-Cabrera R, Scorrano L, Zeviani M, Vallese F, Zoratti M, Paradisi C, Argenton F, Brini M, Calì T, Dupont S, Szabò I, Leanza L: Impaired mitochondrial ATP production downregulates Wnt signaling via ER stress induction. Cell Rep 2019; 28:1949-1960.

8 Szabo I, Bock J, Jekle A, Soddemann M, Adams C, Lang F, Zoratti M, Gulbins E: A novel potassium channel in lymphocyte mitochondria. J Biol Chem 2005;280:12790-12798.

9 Szabo I, Bock J, Grassmé H, Soddemann M, Wilker B, Lang F, Zoratti M, Gulbins E: Mitochondrial potassium channel Kv1.3 mediates Bax-induced apoptosis in lymphocytes. Proc Nat Acad Sci U S A 2008;105:1486114866.

10 Szabo I, Soddemann M, Leanza L, Zoratti M, Gulbins E: Single-point mutations of a lysine residue change function of Bax and Bcl-xL expressed in Bax- and Bak-less mouse embryonic fibroblasts: novel insights into the molecular mechanisms of Bax-induced apoptosis. Cell Death Differ 2011;18:427-438.

11 Bednarczyk P, Kowalczyk JE, Beresewicz M, Dołowy K, Szewczyk A, Zabłocka B: Identification of a voltage-gated potassium channel in gerbil hippocampal mitochondria. Biochem Biophys Res Commun 2010;397:614-620.

12 Comes N, Bielanska J, Vallejo-Gracia A, Serrano-Albarrás A, Marruecos L, Gómez D, Soler C, Condom E, Ramón Y Cajal S, Hernández-Losa J, Ferreres JC, Felipe A: The voltage-dependent K(+) channels Kv1.3 and Kv1.5 in human cancer. Front Physiol 2013;4:283.

13 Deutsch C, Chen LQ: Heterologous expression of $\mathrm{K}^{+}$channels in $\mathrm{T}$ lymphocytes: functional consequences for volume regulation. Proc Natl Acad Sci 1993;90:10036-10040.

14 Abraham RT, Weiss A: Jurkat T cells and development of the T-cell receptor signaling paradigm. Nat Rev Immunol 2004;4:301-308.

15 Manning AM, Davis RJ: Targeting JNK for therapeutic benefit: from junk to gold? Nat Rev Drug Discov 2003;2:554-565.

16 Ventura JJ, Kennedy NJ, Lamb JA, Flavell RA, Davis RJ: c-Jun NH -terminal kinase is essential for the regulation of AP-1 by tumor necrosis factor. Mol Cell Biol 2003;23:2871-2882.

17 Tournier C, Hess P, Yang DD, Xu J, Turner TK, Nimnual A, Bar-Sagi D, Jones SN, Flavell RA, Davis RJ: Requirement of JNK for stress-induced activation of the cytochrome c-mediated death pathway. Science 2000;288:870-874.

18 Imose M, Nagaki M, Naiki T, Osawa Y, Brenner DA, Asano T, Hayashi H, Kato T, Moriwaki H: Inhibition of nuclear factor kappaB and phosphatidylinositol 3-kinase/Akt is essential for massive hepatocyte apoptosis induced by tumor necrosis factor alpha in mice. Liver Int 2003;23:386-396.

19 Kulik G, Klippel A, Weber MJ: Antiapoptotic signalling by the insulin-like growth factor I receptor, phosphatidylinositol 3-kinase, and Akt. Mol Cell Biol 1997;17:1595-1606.

20 Franke TF, Kaplan DR, Cantley LC: PI3K: downstream AKTion blocks apoptosis. Cell 1997;88:435-437.

21 Kauffmann-Zeh A, Rodriguez-Viciana P, Ulrich E, Gilbert C, Coffer P, Downward J, Evan G: Suppression of c-Myc-induced apoptosis by Ras signalling through PI(3)K and PKB. Nature 1997;385:544-548.

22 Chiara F, Rasola A: GSK-3 and mitochondria in cancer cells. Front Oncol 2013;3:16.

23 Bernardi P, Rasola A, Forte M, Lippe G: The mitochondrial permeability transition pore: channel formation by F-ATP synthase, integration in signal transduction, and role in pathophysiology. Physiol Rev 2015;95:1111-1155.

24 Sugiyama MG, Fairn GD, Antonescu CN: Akt-ing up just about everywhere: compartment-specific Akt activation and function in receptor tyrosine kinase signaling. Front Cell Dev Biol 2019;7:70. 